\title{
QUESTÕES METODOLÓGICAS DE WALTER BENJAMIN APLICADAS AO DRAMA BARROCO DOS EXILADOS DO NORDESTE
}

\author{
Lucili Grangeiro Cortez ${ }^{1}$
}

\section{RESUMO}

$\mathrm{O}$ artigo trata da metodologia adotada pela autora na pesquisa que deu origem ao livro $O$ drama barroco dos exilados do Nordeste, o qual teve como objetivo o estudo da trajetória política de nordestinos que tentaram reaver a identidade cultural e política perdida, envolvendo-se no cotidiano social e político dos países que os receberam, após o golpe civil-militar de 1964, no Brasil. Os elementos teóricos trabalhados por Walter Benjamin em Origem do drama barroco alemão, O Narrador e as Teses Sobre o Conceito de História foram adotados diante da identificação, no discurso dos exilados, do uso da alegoria, da defesa das utopias, das idéias românticas, dos fatos e das situações vivenciadas com o banimento, a tortura, a morte, a melancolia etc. Através da inspiração do conteúdo dos elementos trabalhados por esse autor, foi possível perceber as afinidades dos exilados políticos com o herói do "drama barroco", utilizando-se a recorrência aos dramas históricos e políticos de William Shakespeare, os quais retratam o cotidiano do início do Estado Moderno,

Palavras-Chave: Exílio, Expatriamento, Melancolia, Discurso alegórico, Romantismo, Nacionalismo

\section{ABSTRACT}

The scope of this paper is the methodology adopted by the author in the research which gave origin to her book The Baroque Drama of Northeastern Exiled Brazilians, whose objective was to study the political trajectory of those Northeastern exiled who tried to get back their cultural and political identity, involving themselves into the political and social daily life of the countries which received them after the 1964 civilmilitary Coup d'État in Brazil. The theoretical elements treated by Walter Benjamin in his Origin of the German Baroque Dream on their historical concept as elaborated by the Narrator and the Thesis, were adopted in face of their identification into the expatriates discourse, such as the use of allegories in defense of the utopias, of romantic ideas, of facts and situations endured by banishment, torture, melancholy, etc. Through the contents of the elements worked up by this Author, it was possible to identify the affinity of the political exiled with "baroque drama", by utilizing the recurrence of Shakespeare's historic and political dramas which portrayed daily life at the beginning of Modern State

Key words: Exile, Expatriates, Melancholy, Allegoric discourse, Romanticism, Nationalism

\section{INTRODUÇÃ̃O}

As afinidades encontradas entre os elementos empíricos identificados na trajetória política dos exilados nordestinos do período da ditadura civil-militar e a teoria de Walter Benjamin, possibilitaram a adoção dos conceitos e da metodologia, que se encontram dispersos em toda sua obra, privilegiando-se no presente estudo as Teses apresentadas em Sobre o conceito da História, Origem do drama barroco alemão e $O$ narrador.

\footnotetext{
${ }^{1}$ Lucili Grangeiro Cortez é Professora dos Cursos de Ciências Sociais e de História do Centro de Humanidades da Universidade Estadual do Ceará. Doutora em História pela Universidade Federal de Pernambuco e autora do livro O drama barroco dos exilados do Nordeste. Fortaleza: UFC/UFPE/UECE, 2005.
} 
A narrativa de um acontecimento histórico como uma peça de teatro tem sido um recurso metodológico adotado no campo das Ciências Humanas, entendendo-se que a Arte e a Estética têm fundamento ou inspiram-se na realidade cotidiana. Portanto, através da reconstrução da memória do exílio e da análise do discurso dos exilados, verdadeiros "arquivos vivos", a ditadura militar como um acontecimento político ocorrido na sociedade brasileira e a história (Geschichte) ${ }^{2}$ desses personagens como um drama são narradas a partir do cenário que compreende início do governo do Presidente João Goulart até o retorno do País à legalidade. A narrativa envolveu o cenário político que antecedeu o golpe, as lutas travadas pela manutenção ou derrubada do pólo de poder, o imaginário ou as idéias como visão de mundo que davam lugar à ação política e à representação dos exilados nordestinos como personagens de um drama político.

Através da noção de tempo, o tempo do calendário, um dos objetos do presente estudo, ao contrário do tempo do relógio, a existência de sujeitos políticos foi demarcada mediante a "recordação"(Eingedenken) e de momentos que capturaram o tempo em "pontos de concentração". Nesses "dias de recordação", nos "momentos de recordação", as coisas relembradas subitamente se tornaram "atuais", retornaram à existência. Segundo Olgária Matos, esse é o caráter diferencial do tempo histórico: "não a badalada regular do relógio que nivela todas as ocorrências em um contínuo indiferente, mas a súbita pausa do colecionador; não o frio avanço do progresso infinito, mas sua transgressão". ${ }^{3}$ Assim, a noção de tempo foi tomada como indício na observação da narrativa dos acontecimentos durante as entrevistas, pois os abusos e a tortura a que foram submetidos ainda produzem sofrimento. Em várias sessões de entrevista, os exilados choraram ao relembrar os fatos ou fugiram do assunto, embora, no atual momento, estejam chegando ao conhecimento público documentos e denúncias que antes não eram divulgados. Os relatos dos exilados com maior ou menor peso político ou com participação no campo de poder receberam a mesma relevância e, assim, através das narrativas e da análise das histórias de vida buscou-se resgatar a memória do período em estudo, distinguindo "o tempo controlado por relógios do tempo pontuado pelo calendário."4

\section{METODOLOGIA PARA UMA HISTÓRIA BARROCA.}

Benjamin constrói uma metodologia em oposição à adotada pelas ciências modernas, criticando os métodos das ciências humanas, tanto da filosofia como da história ou do historicismo, defendendo o que entende como uma historiografia materialista. Ele critica a historiografia tradicional ou a "escola metódica",

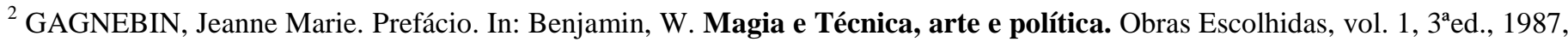
p.7. O termo Geschichte, segundo explica Gagnebin, "como 'história', designa tanto o processo de desenvolvimento da realidade no tempo como o estudo desse processo ou um relato qualquer"...trata-se de "uma reflexão crítica sobre nosso discurso a respeito da história (das histórias), discurso esse inseparável de uma certa prática. Assim, a questão da escrita da história remete às questões mais amplas da prática política e da atividade da narração".

${ }^{3}$ MATOS, Olgária. Os arcanos do inteiramente outro. 2. ed. São Paulo: Brasiliense, 1989. p. 32

${ }^{4}$ Idem, p. 33.
} 
afirmando que "o historicismo culmina legitimamente na história universal", com um método que "não tem qualquer armação teórica", cujo "procedimento é aditivo", pois

\begin{abstract}
... "utiliza a massa dos fatos, para com eles preencher o tempo homogêneo e vazio. Ao contrário, a historiografia marxista tem em sua base um princípio construtivo... O materialista histórico só se aproxima de um objeto histórico quando o confronta enquanto mônada... Ele aproveita essa oportunidade para extrair uma época determinada do curso homogêneo da história; do mesmo modo, ele extrai da época uma vida determinada. Seu método resulta em que na obra, o conjunto da obra, no conjunto da obra a época e na época a totalidade do processo histórico são preservados e transcendidos. O fruto nutritivo do que é compreendido historicamente contém em seu interior o tempo, como sementes preciosas, mas insípidas". 5
\end{abstract}

Gagnebin explica que Benjamin, ao contrário do historicismo que se volta para uma "imagem eterna do passado" ou para uma "teoria do progresso, para a de futuros que cantam, o historiador deve construir uma 'experiência' (Erfahrung) com o passado". ${ }^{6}$ No Apêndice 1 das Teses Benjamin afirma que, ao contrário do historicismo, que "se contenta em estabelecer um nexo causal entre vários momentos da história", o "historiador consciente" desse problema busca captar "a configuração em que sua própria época entrou em contato com uma época anterior, perfeitamente determinada". Benjamin critica o método adotado pelo historicismo ao explicar que "nenhum fato, meramente por ser causa, é só por isso um fato histórico". Esses momentos se transformam em fatos históricos posteriormente, "graças a acontecimentos que podem dele estar separados por milênios". 7 Segundo Benjamin, o historiador ou o filósofo,

...consciente disso renuncia a desfiar entre os dedos os acontecimentos, como as contas de um rosário. Ele capta a configuração em que sua própria época entrou em contato com uma época anterior, perfeitamente determinada. Com isso ele funda um conceito do presente como um 'agora' no qual se infiltraram estilhaços do messiânico. ${ }^{8}$

No Prefácio de Magia e técnica, arte e política, Gagnebin identifica a influência da estética de Proust nas Teses defendidas em Sobre o Conceito de História, nas quais Benjamin desenvolve recomendações metodológicas ao "historiador "materialista",

A mesma preocupação de salvar o passado no presente graças à percepção de uma semelhança que transforma os dois: transforma o passado porque este assume uma forma nova, que poderia ter desaparecido no esquecimento; transforma o presente porque este se revela como sendo a realização possível dessa promessa anterior, que poderia ter-se perdido para sempre, que ainda pode se perder se não a descobrirmos, inscrita na linha do atual ${ }^{9}$

No Prefácio de Origem, Benjamin apresenta os pressupostos de seu método, cuja argumentação assume a forma do tratado. Critica, inicialmente, a matemática por rejeitar essa forma, ao eliminar o problema da representação reivindicada por qualquer sistema didático eficaz como "sinal do conhecimento

\footnotetext{
${ }^{5}$ BENJAMIN, Walter. Sobre o conceito da História. Tese $n^{\circ} 17$. In: Magia e técnica, arte e política. $3^{\mathrm{a}}$ ed. São Paulo:

Brasiliense, 1987, p. 231

${ }^{6}$ GAGNEBIN, op. cit., p. 8

${ }^{7}$ Ibidem, p. 232.

${ }^{8}$ BENJAMIN, 1987, Apêndice 1, p. 232

${ }^{9}$ GAGNEBIN, Anne Marie. Prefácio. In: Benjamin, 1987, p. 16
} 
genuíno", renunciando à "esfera visada pela linguagem", que é uma característica desse tipo de argumentação e de apresentação. Para Benjamin,

Os tratados podem ser didáticos no tom, mas em sua estrutura interna não têm a validade obrigatória de um ensino, capaz de ser obedecido, como a doutrina, por sua própria autoridade. Os tratados não recorrem, tampouco, aos instrumentos coercitivos da demonstração matemática. Em sua forma canônica, só contém um único elemento: a citação autorizada. A quintessência de seu método é a representação. Método é caminho indireto, é desvio. A representação como desvio é portanto a característica do tratado. ${ }^{10}$

A natureza básica do tratado consiste na renúncia à intenção em um movimento contínuo, incansável, pois "o pensamento começa sempre de novo, e volta sempre, minuciosamente, às próprias coisas". Esse "fôlego infatigável é a mais autêntica forma de ser da contemplação", recomendando que um mesmo objeto deve ser considerado nos vários estratos de sua significação, recebendo, ao mesmo tempo, um estímulo para o "recomeço perpétuo e uma justificação para a intermitência do seu ritmo". E, assim, é composto o "mosaico", que surge como o modelo, cujos fragmentos compõem o desenho, a forma final. Em Origem, Benjamin explica:

Tanto o mosaico como a contemplação, justapõem elementos isolados e heterogêneos, e nada manifesta com mais força o impacto transcendente, quer da imagem sagrada, quer da verdade. $\mathrm{O}$ valor desses fragmentos de pensamento é tanto maior quanto menor sua relação imediata com a concepção básica que lhes corresponde, e o brilho da representação depende desse valor da mesma forma que o brilho do mosaico depende da qualidade do esmalte. A relação entre o trabalho microscópico e a grandeza do todo plástico e intelectual demonstra que o conteúdo de verdade só pode ser captado pela mais exata das imersões nos pormenores do conteúdo material. Em sua forma mais alta, no Ocidente, o mosaico e o tratado pertencem à Idade Média... ${ }^{11}$

A partir de tais pressupostos metodológicos, em Origem do drama barroco alemão, Benjamin vai retomar a ideia de Darstellung (ator) e a representação enquanto se passa o drama. Nessa obra, Benjamin analisa peças de teatro escritas por autores alemães que foram pouco conhecidas e não encenadas. Ao ser acusado de escrever sobre "literatura morta" estava, na realidade, realizando uma revisão do "barroco" como conceito e da forma como era utilizado pelos "historiadores de literatura". Segundo Olgária Matos, o Trauerspiel $^{12}$ abrange "o Barroco, os elizabetanos, Calderón e os dramaturgos alemães, devendo ser mais caracterizado como cenário”, um cenário fúnebre. ${ }^{13}$ Em meio de uma crise geral, Benjamin, influenciado

\footnotetext{
${ }^{10}$ BENJAMIN, W. Origem do drama barroco alemão. São Paulo: Brasiliense, 1984, p. 49

${ }^{11}$ BENJAMIN, 1984. p. 49 - 51.

${ }^{12}$ ROUANET, S. P. Apresentação. In: Benjamin, 1984, op. cit., p. 17 - 18, explica: "A palavra Trauerspiel - drama barroco - em sua existência empírica é o fenômeno, e como Nome é a idéia... São esses elementos que a investigação estrutural descobrirá no drama, e que coincidem com a concepção barroca da história... Spiel, que agora significa jogo e folguedo, remete ao estado de natureza, em que os sons são 'a esfera da locução livre e primordial da criatura'. Trauer designa a tristeza do exílio, que expulsou os sons, esfera da linguagem adamítica, escravizando 'as coisas nos 'amplexos' da significação".

${ }^{13}$ MATOS, op. cit., p. 33; BARROS, Marcos A. de. História e utopia: a crítica e a ampliação da concepção de história na modernidade em Walter Benjamin. 1995. 187f. Dissertação (Mestrado em História) - Universidade Federal de Pernambuco, Recife. p. 49 - 50.
} 
por Nietzsche, apresenta uma nova forma de História e critica a visão historicista, defendendo a necessidade de desconstruir o discurso do vencedor. Em Magia e técnica, arte e política, Benjamin afirma que "o verdadeiro sujeito da história são os oprimidos, pois eles carregam consigo o sentido supremo da história que é a busca da felicidade." 14

Benjamin considera Shakespeare e Calderón os autores barrocos mais importantes, mas a recorrência à obra do primeiro, no presente estudo, deveu-se ao fato desse autor dramatizar as questões de Estado, as lutas pelo poder e o exílio, em Hamlet, Henrique IV, Henrique V, Rei Lear, Júlio César, Coriolano etc. Nessas obras, os diálogos de conteúdo político, ético, filosófico, histórico, sociológico etc., tratam de questões que são objeto de atenção dos exilados e da característica melancólica que lhes é própria. ${ }^{15}$ Nessa relação intrínseca entre a literatura e o acontecimento político, Shakespeare é considerado um fenômeno cultural por ter produzido suas peças a partir de crises sócio-políticas. Embora o protagonista principal dos dramas barrocos tenha "uma condição principesca", o objetivo das tramas é "ilustrar a fragilidade das criaturas", que é "mais visível nas de alta linhagem”, mas seus personagens não pertencem apenas à aristocracia. O Trauerspiel, como forma, "reflete a visão barroca da história como crônica", apresentando acontecimentos no palco do "poderio do mundo", envolvendo príncipes, papas, imperatrizes, cortesãos, mascarados e envenenadores. ${ }^{16}$ Para Harold Bloom , embora Shakespeare celebre a vida em suas peças, indo além da tragédia, a sombra do niilismo perpassa quase toda sua obra como em Nietzsche e Benjamim. ${ }^{17}$ Rouanet também concorda com esta versão ao entender que o drama barroco, numa primeira interpretação, "designa a tristeza de um homem privado da transcendência”, considerando que esses são os elementos que a “investigação estrutural descobrirá no drama, e que coincidem com a concepção barroca da história”. ${ }^{18}$

\section{HISTÓRIA E NARRATIVA}

Para Benjamin, as idéias são o objeto da investigação. Como a idéia é "algo de lingüístico, é o elemento simbólico presente na essência da palavra", a tarefa do filósofo é "restaurar em sua primazia, pela representação, o caráter simbólico da palavra, no qual a idéia chega à consciência de si, o que é o oposto de qualquer comunicação dirigida para o exterior." Portanto, essa tarefa só pode ser cumprida pala reminiscência, pois "a filosofia não pode ter a arrogância de falar no tom da revelação". Esse gênero de reminiscência é um tipo de investigação que tem semelhanças com a anamnesis platônica. ${ }^{19}$

\footnotetext{
${ }^{14}$ BENJAMIN, 1987, op. cit. p. 222 - 232.

${ }^{15}$ Sobre a melancolia ver BENJAMIN, 1984, op. cit. p. 168 - 180; GIVONE, Sergio. El Intelectual. In: FURET, François et al. El hombre romântico. Madrid: Alianza Editorial, 1997. p. 259 - 263.

${ }^{16}$ MATOS, op. cit., p. 33.

${ }^{17}$ BLOOM, Harold. Shakespeare: a invenção do humano. Rio de Janeiro: Objetiva, 2000. p. 30, 35 - 37, $39,222$.

${ }^{18}$ ROUANET, op. cit., p.18, 29.

${ }^{19}$ BENJAMIN, 1984, p. 60
} 
Benjamin alerta o pesquisador para perceber que "a relação ingênua entre o ouvinte e o narrador é dominada pelo interesse em conservar o que foi narrado", lembrando que "para o ouvinte imparcial, o importante é assegurar a possibilidade da reprodução, pois a memória é a mais épica de todas as faculdades"20

Benjamin explica:

"A experiência que passa de pessoa a pessoa é a fonte a que recorrem todos os narradores. E, entre as narrativas escritas, as melhores são as que menos se distinguem das histórias orais contadas pelos inúmeros narradores anônimos. Entre estes, existem dois grupos, que se interpenetram de múltiplas maneiras. A figura do narrador só se torna plenamente tangível se temos presente esses dois grupos. 'Quem viaja tem muito que contar', diz o povo, e com isso imagina o narrador como alguém que vem de longe. Mas também escutamos com prazer o homem que ganhou honestamente sua vida sem sair do país e que conhece suas histórias e tradições....Na realidade , esses dois estilos de vida produziram de certo modo suas respectivas famílias de narradores. Cada uma delas conservou, no decorrer dos séculos, suas características próprias. ..No entanto, essas duas famílias, como já se disse, constituem apenas tipos fundamentais. A extensão real do reino narrativo, em todo o seu alcance histórico, só pode ser compreendido se levarmos em conta a interpenetração desses dois tipos arcaicos. ${ }^{21}$

Assim, Benjamin recomenda seguir a trilha de Leskov ${ }^{22}$ e ouvir a "voz da natureza", na expectativa de que a narrativa deixe o leitor descobrir e interpretar o sentido da história. Benjamin descreve a capacidade do narrador em assimilar também “à sua substância mais íntima aquilo que sabe por ouvir dizer”, no caso específico, aquele que narra os relatos das histórias de vida, como também chama a atenção para o entrevistado, para aquele que tem o "dom"... "de contar sua vida inteira". ${ }^{23}$ Segundo esse autor:

A narrativa, que durante tanto tempo floresceu num meio artesão - no campo, no mar e na cidade - é ela própria, num certo sentido, uma forma artesanal de comunicação. Ela não está interessada em transmitir o "puro em si" da coisa narrada como uma informação ou um relatório. Ela mergulha a coisa na vida do narrador para em seguida retirá-la dele. Assim se imprime na narrativa a marca do narrador, como a mão do oleiro na argila do vaso. ${ }^{24}$

Para Juergen Franzke, a narração, além de implicar a adesão a certas regras formais do esquema lingüístico apropriado, também significa ter presente a motivação, ou seja, a narração de uma história que seja interessante e atraente ao mesmo tempo. Conseqüentemente, na apresentação da própria história de vida, o motivo estético desempenha um importante papel na criação da narrativa, para a qual o termo "aura", adotado por Benjamin ${ }^{25}$, permite aprofundar a idéia. A percepção estética não configura uma imagem da realidade verdadeira, e sim um mito da realidade, a forma ilusória desta. Portanto, as histórias de vida são

\footnotetext{
${ }^{20}$ Idem, p. 210

${ }^{21}$ BENJAMIN, 1987, p. 198

22 BENJAMIN, 1987, Tese no 17, p. 209 - 210. Benjamin cita Nicolai Leskov (1831-1895), escritor russo nascido em São Petersburgo, (que tinha afinidades com Tolstoi, por se interessar pelos camponeses, e com Dostoievski, pela orientação religiosa), como o autor que "mais claramente demonstra esse fenômeno".

${ }^{23}$ Idem, p. 221.

${ }^{24}$ Idem, 1987, p. 205

${ }^{25}$ Para BENJAMIN, 1984, p. 170, a aura como uma "figura singular" compõe-se de elementos "espaciais e temporais". A aura é a "aparição única de uma distância, por mais perto que ela esteja. Observar em repouso, numa tarde de verão, uma cadeia de montanhas no horizonte, ou um galho, que projeta sua sombra sobre nós, significa respirar a aura dessas montanhas, desse galho".
} 
produtos literários que também são formulados segundo as leis da beleza, devendo possuir unicidade e permanência. ${ }^{26}$

Diante da observância de tais pressupostos, o "drama barroco" foi adotado como uma alegoria para compreender a ditadura militar no Brasil, por tratar de questões políticas, do martírio do herói ou do monarca, um "estóico radical", cujo "momento de provação se dá durante um conflito com a coroa ou uma disputa religiosa", com um desfecho que significa para ele a tortura e a morte. Trata também da função do tirano na "restauração da ordem, durante o Estado de Exceção"... ${ }^{27}$ Com inspiração neste tipo de abordagem foi possível discutir e narrar os acontecimentos que provocaram o banimento ou a saída do Brasil de atores sociais e políticos ${ }^{28}$, que se depararam com o "efêmero, o acaso", entrando "em contato com um mundo de ruínas e de morte", de "progresso e de eterno retorno". Na representação dos acontecimentos do período em estudo, através da narrativa dos exilados, recorreu-se à perspectiva da "teatralidade como história" ou de uma "visão trágica da história", tomando de empréstimo termos adotados por Olgária Matos. ${ }^{29}$

\section{CONCLUSÃO: o passado no presente}

O "drama barroco" forneceu os elementos subjetivos, psicológicos e analíticos para compreensão do drama do exilado político do Nordeste do Brasil, durante o Estado de Exceção, ao ser despojado da identidade social e política. Nos relatos dos exilados são identificadas as cenas de terror, a sensação de um mundo em ruínas, fragmentado, decadente, que são os elementos conceituais de Benjamin, como também a tragédia, a melancolia e a acedia $^{30}$, o discurso alegórico através do qual eles representam o papel do herói como um tipo político e a correspondente visão de mundo romântica.

A recomendação de Benjamin ao pesquisador que adotar o método do materialismo histórico é a de se aproximar de um objeto histórico confrontando-o enquanto "mônada", descobrindo a "oportunidade revolucionária de lutar por um passado oprimido". 31

Como a ditadura civil-militar é um acontecimento recente, cujos personagens do drama ainda estão vivos em sua maioria, tanto os que assumiram o poder como os dominados ou vencidos, muitos fatos não

\footnotetext{
${ }^{26}$ FRANZKE, Juergen. El mito de la historia de vida: In: Historia e Fuentes orales. Barcelona: Universitat de Barcelona, 1992, p. $60-61$.

${ }^{27}$ Ibidem, p. 97.

${ }^{28}$ Embora se reconheça que os exilados eram atores sociais e políticos diante do papel que representavam na sociedade brasileira, no entanto estão caracterizados nesta pesquisa como "personagens alegóricos" (Benjamin, 1984, p. 23 - 24) pelo caráter eventual da situação do exílio e, também como elemento da representação, pois "o drama barroco não tem heróis somente configurações" (idem, p. 9).

${ }^{29}$ MATOS, op. cit. p. $31-58$.

30 BENJAMIN, 1984, op. cit. p. 177 - 178, apresenta o conceito teológico da melancolia de Albertinus, o qual entende a acedia como um dos pecados capitais, "a inércia do coração". No drama barroco, a acedia ou indolência é a indecisão do Príncipe. Nos fundamentos astrológicos, há uma relação entre a acedia e o melancólico, produzida pela luz baça e a lentidão da órbita de Saturno. Sobre o mesmo assunto, ver MATOS, 1989, p. 33; GADAMER, 1997, p. 212 - 218; ARISTÓTELES. O homem de gênio e a melancolia: o problema XXX, 1. Rio de Janeiro: Lacerda, 1998.

${ }^{31}$ BENJAMIN, 1987. p. 231.
} 
são do conhecimento público, havendo necessidade de se trabalhar com as "memórias fragmentadas" para compor o "mosaico" ou construir um mapeamento na elaboração da trama, segundo a metodologia de Benjamin. ${ }^{32}$ Ao adotar, segundo recomendação desse autor, uma "orientação necessária para os extremos", buscou-se uma "visão completa e imparcial do objeto", guiada pelo pressuposto de que os elementos iriam se unir "nos conceitos adequados, como partes integrantes de uma síntese". ${ }^{33}$

Portanto, a opção metodológica em adotar o drama do período barroco, como uma alegoria possibilitou a compreensão de um acontecimento da Era contemporânea, pois, de acordo com a definição etimológica, “alegoria é o discurso por meio do "outro"”. Além dessa definição, Willi Bolle explica a alegoria como "a antítese da mercadoria", por ter sido "um instrumento de desvalorização da iconografia pagã" na Idade Média e "um signo de legitimação do poder" no período do Absolutismo. Esse autor ressalta a descoberta do potencial dialético da utilização metodológica da alegoria por Baudelaire e Benjamin que passaram a adotála "como um meio de desmascarar o fetichismo mercantil e de descobrir os mitos da modernidade (Novidade, Progresso, Eterno Retorno)”. Para esse autor, a alegoria não tem um caráter apenas destruidor, "mas pode resgatar potenciais de sentido contido nos mitos". 34

A idéia de adotar uma "historiografia alegórica" para estudar uma época a partir de outra, favoreceu a "percepção mais aguda" da própria época ou da cultura. Segundo Willi Bolle, Benjamin recomenda ao historiador trabalhar o passado de forma a iluminar o presente, no que consiste uma relação, pois aquilo que desperta o passado é despertado por elementos do presente. O que define esse conhecimento é o "sonho", um misto de sonho que desperta do pesadelo. A tarefa do pesquisador é entender esse sonho, cabendo-lhe despertar e interpretá-lo. Portanto, a fonte de percepção da História está situada no presente do historiador. ${ }^{35}$

Benjamin defende a posição do historiador ou do filósofo como um guardião da história da humanidade, referindo-se à situação da Europa nos conflitos da Segunda Guerra Mundial, situação que ainda pode ser identificada, não só no período da ditadura militar no Brasil, como também na sociedade contemporânea. Na Tese 8 ele recomenda:

A tradição dos oprimidos nos ensina que o 'estado de exceção' em que vivemos é na verdade a regra geral. Precisamos construir um conceito de história que corresponda a essa verdade. Nesse momento, percebemos que nossa tarefa é originar um verdadeiro estado de exceção; com isso, nossa posição ficará mais forte na luta contra o fascismo... O assombro com o fato de que episódios que vivemos no século XX 'ainda' sejam possíveis, não é um assombro filosófico. Ele não gera nenhum conhecimento, a não ser o conhecimento de que a concepção de história da qual emana semelhante assombro é insustentável. ${ }^{36}$

\footnotetext{
${ }^{32}$ Idem, p. 50 - 51.

${ }^{33}$ Ibidem, p. $81-82$.

${ }^{34}$ BOLLE, Willi. As siglas em cores no Trabalho das Passagens de W. Benjamin. Estudos Avançados. São Paulo, v. 10, n 27, p. 66, maio./ago. 1996; Idem, Gêneros Literários Urbanos. Berlim, Paris, São Paulo. Revista Tempo Brasileiro, n. 132, p. 89 - 90, jan./mar.1998.

${ }^{35}$ BOLLE, Willi. Cf. apontamentos de aula.

${ }^{36}$ BENJAMIN, 1987, op. cit. Tese 8, p. 226.
} 
Como o presente deve ser iluminado pelo passado, uma tarefa que cabe ao historiador, segundo as recomendações de Benjamin na Tese 7, essa abordagem metodológica foi a mais indicada por tratar de um acontecimento recente, cujos personagens ainda estão vivos em sua maioria e as feridas do exílio ainda não cicatrizaram. Mas, segundo esse autor, o pesquisador deve também "escovar a História a contrapelo", buscando resgatar o que não foi dito, o que foi omitido. ${ }^{37}$

Portanto, as questões de método em Walter Benjamin permitem resgatar o passado tornando-o presente e possibilitam ao filósofo, ao cientista social, ao historiador uma visão crítica da realidade a ser pesquisada e uma produção acadêmica criativa. A Tese 9 em Sobre o conceito da História permite finalizar essas considerações sobre o método em Benjamin, a qual reflete o momento que ele estava vivendo na Alemanha nazista e que ainda é bastante atual, fornecendo elementos para discutir as atuais questões sobre o futuro da humanidade:

Há um quadro de Klee que se chama Angelus Novus. Representa um anjo que parece querer afastar-se de algo que ele encara fixamente. Seus olhos estão escancarados, sua boca dilatada, suas asas abertas. $\mathrm{O}$ anjo da história deve ter esse aspecto. Seu rosto está dirigido para o passado. Onde nós vemos uma cadeia de acontecimentos, ele vê uma catástrofe única, que acumula incansavelmente ruína sobre ruína e as dispersa a nossos pés. Ele gostaria de deter-se para acordar os mortos e juntar os fragmentos. Mas uma tempestade sopra do paraíso e prende-se em suas asas com tanta força que ele não pode mais fechá-las. Essa tempestade o impele irresistivelmente para o futuro, ao qual ele vira as costas, enquanto o amontoado de ruínas cresce até o céu. Essa tempestade é o que chamamos de progresso". 38

\section{REFERÊNCIAS}

ARISTÓTELES. O homem de gênio e a melancolia: o problema XXX, 1. Rio de Janeiro: Lacerda, 1998.

BARROS, Marcos A. de. História e utopia: a crítica e a ampliação da concepção de história na modernidade em Walter Benjamin. 1995. 187f. Dissertação (Mestrado em História) - Universidade Federal de Pernambuco, Recife.

BENJAMIN, W. Origem do drama barroco alemão. São Paulo: Brasiliense, 1984

Magia e técnica, arte e política. $3^{a}$ ed. São Paulo: Brasiliense, 1987.

BLOOM, Harold. Shakespeare: a invenção do humano. Rio de Janeiro: Objetiva, 2000.

BOLLE, Willi. As siglas em cores no Trabalho das Passagens de W. Benjamin. Estudos Avançados. São Paulo, v. 10, n 27, p. 66, maio./ago. 1996

jan./mar.1998.

Gêneros Literários Urbanos. Berlim, Paris, São Paulo. Revista Tempo Brasileiro, n. 132, p. 89 - 90,

CORTEZ, Lucili Grangeiro. O drama barroco dos exilados do Nordeste. Fortaleza: UFC/UFPE/UECE, 2005.

FRANZKE, Juergen. El mito de la historia de vida: In: Historia e Fuentes orales. Barcelona: Universitat de Barcelona, 1992

GADAMER, Hans- Georg. Verdade e método. Petrópolis, Rio de Janeiro: Vozes, 1997

GAGNEBIN, Anne Marie. Prefácio. In: Benjamin, 1987,

GIVONE, Sergio. El Intelectual. In: FURET, François et al. El hombre romântico. Madrid: Alianza Editorial, 1997.

MATOS, Olgária. Os arcanos do inteiramente outro. 2. ed. São Paulo: Brasiliense, 1989

ROUANET, S. P. Apresentação. In: Benjamin, 1984.

${ }^{37}$ Ibidem, Tese 7, p. 225.

${ }^{38}$ Tese 9, p. 226 